\title{
Acute Monocytic Leukemia in Remission
}

National Cancer Institute

\section{Source}

National Cancer Institute. Acute Monocytic Leukemia in Remission. NCI Thesaurus. Code C3590.

An acute monocytic leukemia which is not growing and responds to treatment. 